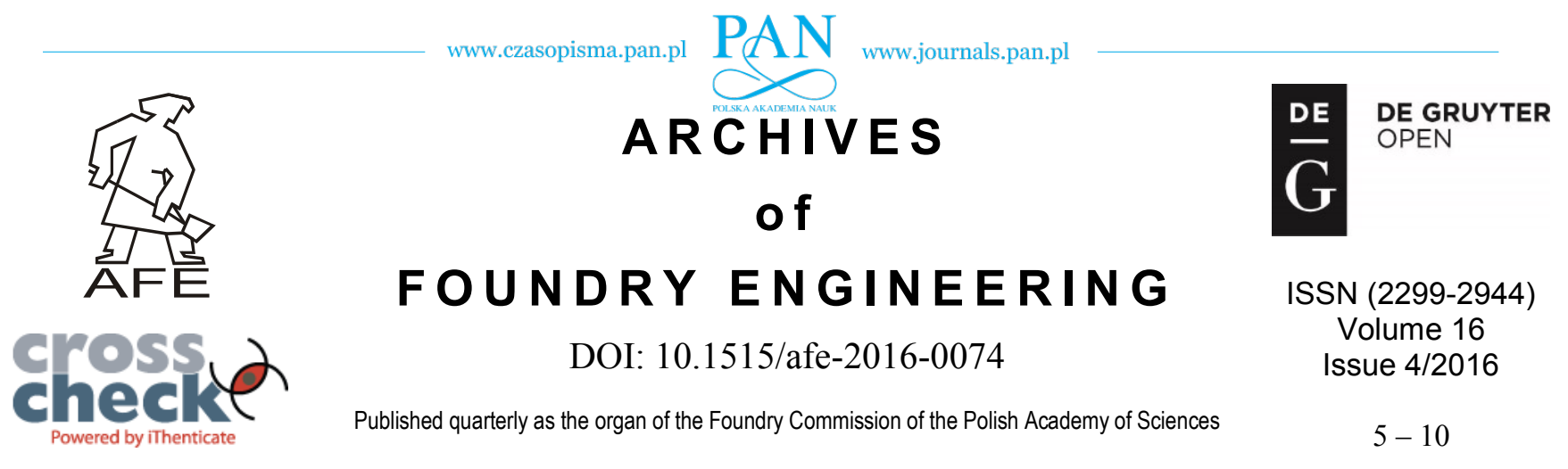

\title{
Parametric Analyses on Compressive Strength of Furan No Bake Mould System Using ANN
}

\author{
S.G. Acharya ${ }^{a, b, *}$, J.A. Vadher ${ }^{c}$ \\ ${ }^{a}$ School of Engineering, R.K.University, Rajkot, INDIA \\ ${ }^{\mathrm{b}}$ Mechanical Engineering Department, SVIT, Vasad, INDIA \\ ${ }^{\mathrm{c}}$ Mechanical Engineering Department, Government Engineering College, Palanpur, INDIA \\ *Corresponding author. E-mail address: shailee.acharya@gmail.com
}

Received 17.03.2016; accepted in revised form 07.06.2016

\begin{abstract}
Casting is the most widely used manufacturing technique. Furan No-bake mould system is very widely accepted in competitive foundry industries due to its excellent characteristics of producing heavy and extremely difficult castings. These castings have excellent surface finish and high dimensional stability. Self setting and high dimensional stability are the key characteristics of FNB mould system which leads to reduce production cycle time for foundry industries which will ultimately save machining cost, labour cost and energy. Compressive strength is the main aspect of furan no bake mould, which can be improved by analyzing the effect of various parameters on it. ANN is a useful technique for determining the relation of various parameters like Grain Fineness Number, Loss on Ignition, $\mathrm{pH}, \%$ resin and temperature of sand with compressive strength of the FNB mould. Matlab version: R2015a version 8.3 software with ANN tool box can be used to gain output of relation. This paper deals with the representation of relationship of various parameters affecting on the compressive strength of FNB mould.
\end{abstract}

Keywords: ANN, Compressive strength, FNB mould, Matlab version: R2015a version 8.3, Parameters

\section{Introduction}

Furan type resin binders were introduced in 1950's as an acid catalyzed no bake furan binder system. In the 1980's, furan resin became the largest resin binder consumed and presently it is the largest selling no-bake system.

FNB is a simple two part binder structure made up an acid catalyst and a reactive type resin. It can be operated for making all types of metal castings in all sizes. Amount of no bake binder taken is usually $0.9 \%-1.2 \%$ based on sand and levels of catalyst vary from $20 \%$ to $40 \%$ based on binder weight.
FNB castings are a trending demand of global industries due to exciting unique properties of high resistance to defects in sand/metal interface, exceptional dimensional stability and superior shakeout with thermal or mechanical reclamation.

These properties of material are constantly being optimized. Results of research on FNB with topics from base i.e.: properties to recycling can be found and investigated in varied range of publications available worldwide. Productions are striving for quality and quality development due to development of modern technologies.

FNB casting is a form of casting and also retains certain casting defects. These castings are termed in different forms by different researchers. Numbers of factors are contributing to 
casting defects so it is difficult to get completely rid of such defects however minimization of certain defects is possible. In current times, casting defects are analyzed by certain tools like Design of experiment, if then rules, historical data analysis, ishikawa charts etc.

The casting data evaluated are applied in assured optimization tolls like ANOVA or taguchi method. These systems gave satisfactory results. However the concept of simulation is growing globally nowadays to save time and money. Genetic algorithm and Artificial Neural Network are promising tools for simulation. Genetic algorithms are optimization methods and computerized search that works similar to

Artificial Neural Networks is also an active tool for simulation. It is nothing but a computational model of human brain. The neurons are organized to form a pattern of connection and a layer formed within and between the layers over weights referred as network design. There are more than $20 \mathrm{NN}$ architectures used in research. The ANN can forecast airlocks, misruns and cracks. ANN is extensively accepted as solution to ill-defined and complex problems.

The Artificial Neural Network (ANN) was applied to increase creation process of steel. The experiments were done to improve the production of steel by optimizing the process parameters of different processes of production of steel such as endless casting. First it was intended only to use in the production of carbon nano materials in arc discharge reactors. Then it was generalized for other purposes too [9]. The fundamentals, computing, design and application of ANN were studied [12].

The study of the improvement of casting process with the assistance of Artificial Neural network (ANN) and realization that industry generally tries to eliminate the imperfections by trial and error method, which is an error-prone and expensive process [2].

Application of Non Destructive Tests such as RT, UT, LPT was done to prove soundness of the castings and also proved satisfaction of all required properties of castings [11]. Researchers produced mould samples by furan no bake binder system and checked the compressive strength of the moulds after 4 hours. Researchers applied ANOVA to optimize the value of resin and acid catalyst used in FNB binder. Their research concluded that compressive strength has major effect on production of castings and major defect in FNB casting is sand inclusion [1].

The two periods can be singled out in every binding process. The first when binding rate increases and the second when binding rate decreases. He also concluded that bench life is shorter than or almost equal to first period before binding rate is reached maximum [4].

Comparison of PNB, APNB and FNB was done to conclude that FNB binder is used in major foundries in India [6]. Optimization of proportions of clay and water were done using RSM, DOE and Mixture design [8].

Comparison and investigation of tensile strength and binding characteristics of sodium silicate binder are necessary to check quality of mould [7]. Casting skin layers with degenerate spheroidal graphite are considered deleterious to mechanical properties and machinability of thin wall ductile iron castings [5].

Changes in the microstructure in the surface layer of experimental castings with presence of silicon, calcium \& iron as well as aluminium, magnesium, oxygen were observed in experimental castings [10]. ANOVA and regression models were developed to know the response values for different combination of input parameters without conducting experiments [3].

This paper presents review on a use of Artificial neural network (ANN) for the casting processes better than the other techniques such as design of experiment (DOE), examination method, casting simulation, cause-effect diagram, genetic algorithm, fuzzy logic. This paper discusses about the experiments faced by ANN method in the area of prediction, optimization, control, monitor, identification, classification, modelling and so on particularly in the field of manufacturing. This paper also discusses about the number of key issues which should be addressed while applying neural network to practical problems.

\section{Experimental Work}

More than 100 Experiments were performed at a foundry named Krislur Castomech Pvt. Ltd located in Bhavnagar, Gujarat to obtain the required results. Furan No bake mould system was used to produce gray cast iron electric motor body. The mould samples were produced by varying th percentage of resin and acid catalyst in the moulding sand. Krislur Castomech Pvt. Ltd collected the data of defect such as sand inclusion defect from the rejected casting due to sand defect.

Focusing more on Compressive strength in detail, causes and we can find preventive measures of sand inclusion defect. After detail identification of process parameters of casting such as GFN, $\mathrm{pH}$, LOI, Resin, Temperature, and try to study the impact on gas porosity defect. The flowrate, molten metal, temperature, pouring time are kept constant. The experiment on physical properties of the sand is carried out as per the IS 1918.

Experiments were conducted at foundry and certain apparatus such as sand binder mixer, mould boxes, hammer, kelson compressive strength testing machine were applied.

\section{Implementation of ANN}

A several amount of data which is been used in parametric analysis problem were collected from a local industry Krislar Castomech Pvt. Ltd, Bhavnagar, Gujarat.

The higher and the lower limits of all the process parameter and the output parameter were collected from the casting company and different research papers. All the input parameters are given as per the table 1 .

Table 1.

Different sand parameters and their values

\begin{tabular}{llll}
\hline Sr no & Name & $\begin{array}{l}\text { Lower } \\
\text { value }\end{array}$ & Upper value \\
\hline 1 & Grain fineness number & 44.1 & 54.9 \\
2 & Loss on ignition & 1.5 & 2 \\
3 & $\mathrm{pH}$ & 3.5 & 4 \\
4 & \% Resin & 0.8 & 0.95 \\
5 & Temperature of sand ('C) & 24 & 47 \\
\hline
\end{tabular}


Neural Networks are the artificial representation of biological neurons of human brain. This neuron system is circulated in parallel around processing system. These neurons are highly interconnected among them. So a NN is nothing but imitation of human brain and that is why these NNs are called Artificial Neural Network (ANN).Implementation of ANN to optimize the sand casting defects is one of the modern techniques used in industries now a day. Prediction of the most optimized conditions for defect free casting is nearly impossible. But all it can be done is minimizing the casting defects as low as possible.

Artificial Neural Network has many forms of algorithms but the most common and famous for optimization is the back propagation algorithm. In back propagation process first the input weights are given randomly and a target is been set. When the program runs it gives outputs and accordingly the network shows the error between the output and the set target values and the Network corrects itself continuously until the network exceeds the minimum error goal possible.

After the input process parameters has been chosen and the higher and lower limits of their value in specific unit has been registered then the final work starts for ANN. At first a program was developed depending on the higher and lower limit values of the process parameters

The data is first generated in the MATLAB VERSION: $\mathrm{R} 2015 \mathrm{~A}$ VERSION 8.3. Then the data is stored in the workspace of the ANN tool of the MATLAB VERSION: R2015A VERSION 8.3. At Network starts calculating by comparing the input values with the target values. The outputs produced are passed on to the set of target values and it goes on and on until the nodes of the output layer compute the final outputs.

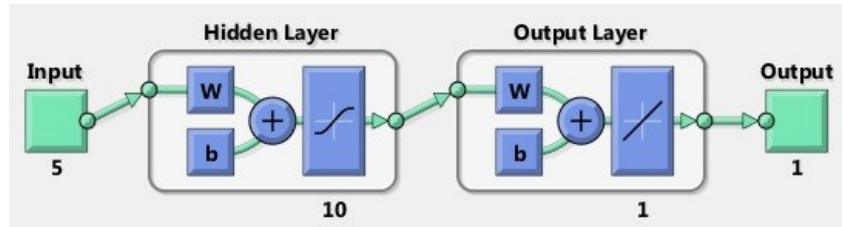

Fig. 1. Network diagram

The network diagram is prepared using $\mathrm{NN}$ tool box in Matlab version: R2015a version 8.3 software, which shows the number of input parameters or variables, output variables and layers. Here six inputs and one output are selected for generating network. Fig. 1 represents the overview of network diagram.

Figure 1 shows a network structure of effect of five different parameters on compressive strength of FNB mould system. This network shows the effect of five inputs on compressive strength of the mould system as a single output.

Figure 1 shows the network diagram created in Matlab version: R2015a version 8.3 software which shows 5 inputs (GFN, LOI, $\mathrm{pH}, \%$ resin, Temperature of sand, 10 layers and 1 output hence the network diagram is created as per given input and desired output. A network is created by putting the data stored in the workspace. Then the network was trained using the parameter values. At first the learning rate is given at minimum 0.1 and in one go 1000 iterations are considered
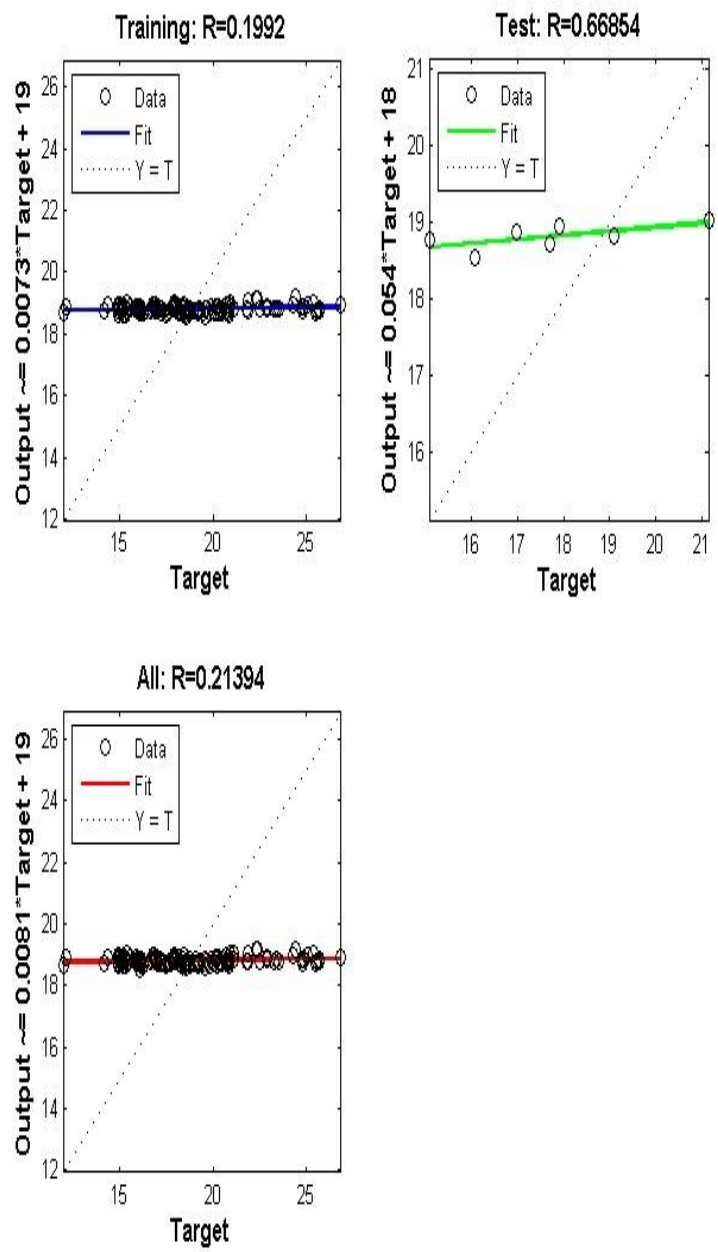

Fig. 2. Regression plot

Regression is accurately generated from the NN tool box as shown in Fig.3, which shows that actual output is lied in trained data, and both output can be compared to measure the accuracy of network. 


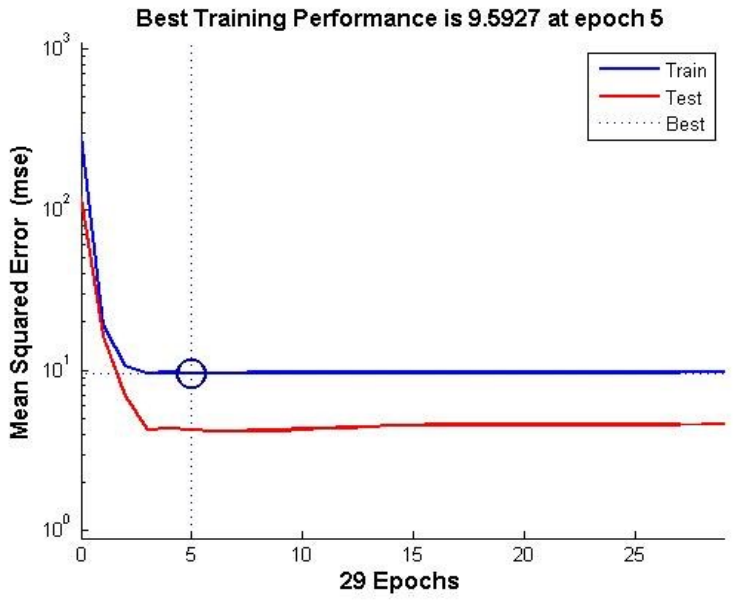

Fig. 3. Mean square error

As shown in fig. 3 mean square error can be reduced at 5 epoch and which gives minimum error for network, and which is allowable to obtain the required results.

The regression curves are generated by several consecutive points obtained from the neural network function so there is no need for plotting of experimental results.

The various parameters are analyzed to determine the effect on compressive strength are as follows

\subsection{The effect of Grain fineness number on compressive strength}

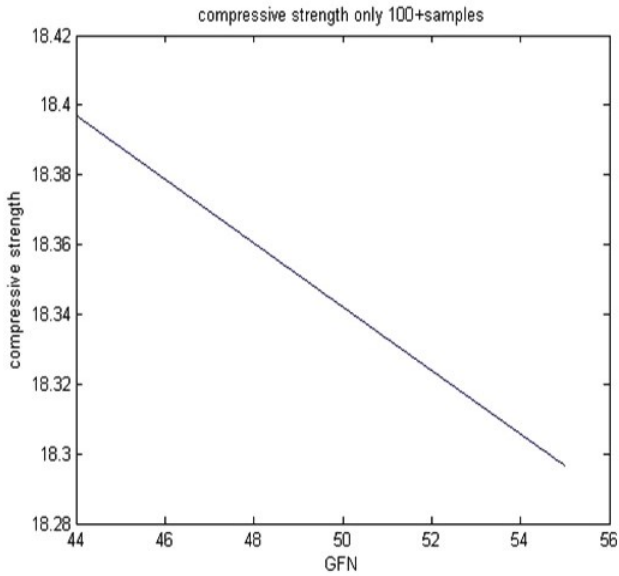

Fig. 4. Compressive strength $\left(\mathrm{kg} / \mathrm{cm}^{2}\right)$ vs GFN

As shown in fig. 4 relation between compressive strength and GFN obtained from ANN analysis. From the graph, it can be observed that at lower value of GFN (near 44) gives the maximum compressive strength while compressive strength linearly decreases over increases of GFN value. So in range of 4456 of GFN, maximum compressive strength can be obtained at lower value of GFN.

\subsection{The effect of Temperature on compressive strength}

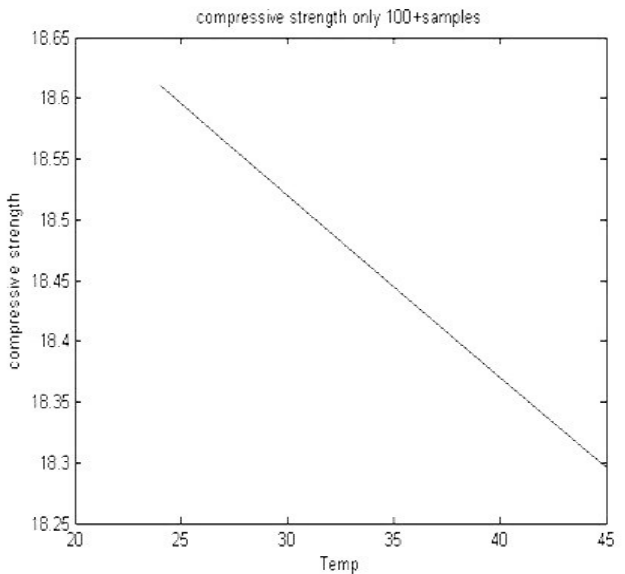

Fig. 5. Compressive strength $\left(\mathrm{kg} / \mathrm{cm}^{2}\right)$ vs Temperature

As shown in fig. 5 relation between compressive strength and Temperature obtained from ANN analysis. From the graph, it can be observed that at lower value of temperature (near 25) gives the maximum compressive strength while compressive strength linearly decreases over increases of temperature value. So in range of 25-45 of GFN, maximum compressive strength can be obtained at lower value of temperature.

\subsection{The effect of $\mathrm{pH}$ value on compressive strength.}

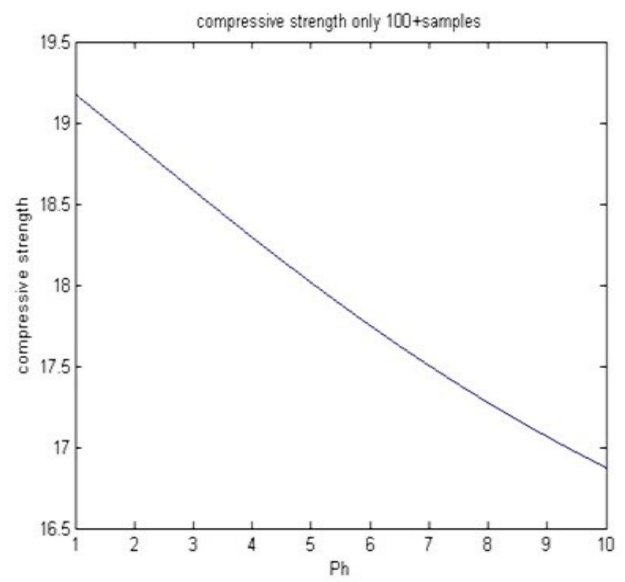

Fig. 6. Compressive strength $\left(\mathrm{kg} / \mathrm{cm}^{2}\right)$ vs $\mathrm{Ph}$

As shown in fig. 6 relation between compressive strength and $\mathrm{Ph}$ obtained from ANN analysis. From the graph, it can be observed that at lower value of $\mathrm{pH}$ (near 1) gives the maximum compressive strength while compressive strength gradually decreases over increases of $\mathrm{pH}$ value. So in range of 1-10 of $\mathrm{pH}$, 
maximum compressive strength can be obtained at lower value of $\mathrm{pH}$.

\subsection{The effect of Loss on ignition on compressive strength.}

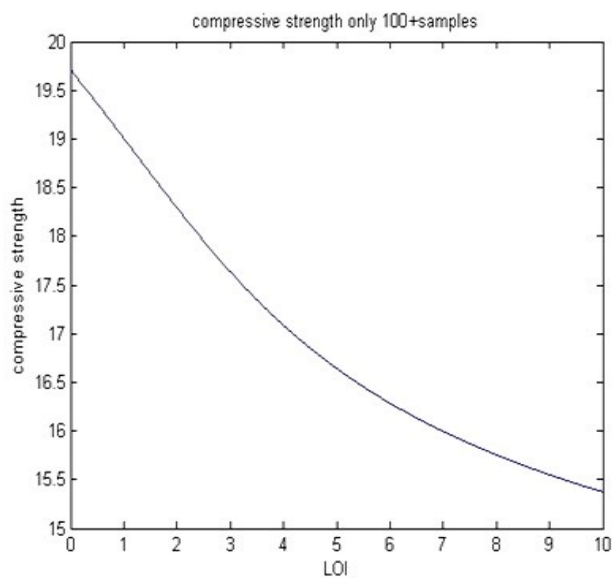

Fig. 7. Compressive strength $\left(\mathrm{kg} / \mathrm{cm}^{2}\right)$ vs LOI

As shown in fig. 7 relation between compressive strength and LOI obtained from ANN analysis. From the graph, it can be observed that at lower value of LOI (near 0) gives the maximum compressive strength while compressive strength gradually decreases over increases of LOI value. So in range of 0-10 of LOI, maximum compressive strength can be obtained at lower value of LOI.

\subsection{The effect of \% Resin in moulding sand on compressive strength.}

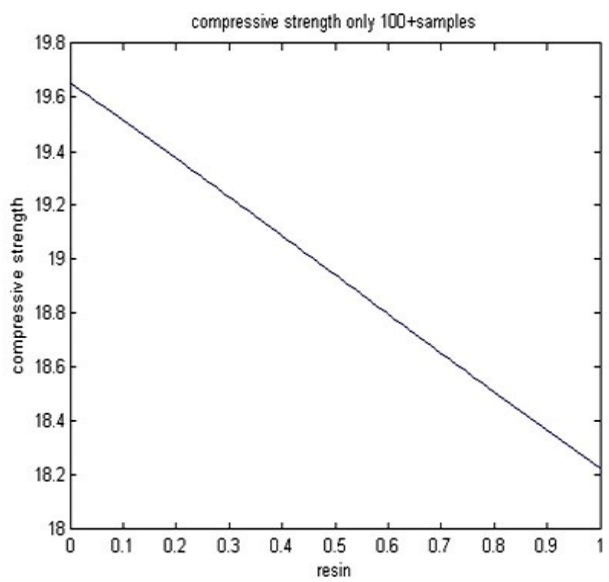

Fig. 8. Compressive strength $\left(\mathrm{kg} / \mathrm{cm}^{2}\right)$ vs Resin As shown in fig. 8 relation between compressive strength and Resin obtained from ANN analysis. From the graph, it can be observed that at lower value of Resin (near 0) gives the maximum compressive strength while compressive strength linearly decreases over increases of Resin value. So in range of $0-1$ of Resin, maximum compressive strength can be obtained at lower value of Resin.

It is necessary to present clearly the main conclusions from the whole paper. It is required to present them in a few points after the general conclusion. The author's achievements and originality of research and the authors' input in the undertaken subject matter and value of study should be emphasised. Practical application and possible directions of further works can be pointed out.

\section{Conclusions}

Parametric analysis has been performed to analyze the effect of various parameters on compressive strength, so more than hundreds of experiments has been performed, and network has been created using NN tool box in Matlab version: R2015a version 8.3 software, which is utilized to obtained the required relation of each parameters on compressive strength. The analysis shows that GFN, temperature and Resin linearly effects on compressive change while LOI and $\mathrm{Ph}$ makes drastically change in compressive strength.

\section{Acknowledgements}

Authors are really acknowledging the help and support from Krislur Castomech Pvt. Ltd., Bhavnagar and Professor Kishan H. Joshi for their valuable help and guidance.

\section{References}

[1] Acharya, S.G., Vadher, J.A. (2015). Experimental investigations on modern furan no bake system to obtain quality casting, Researchgate, International conference on Advances in Materials and Product Science, January.

[2] Patil, G.G. \& Inamdar, K.H. (2014). Prediction of casting defects through Artificial Neural Network. International Journal Of Science, Engineering And Technology. 2(5), 245253.

[3] Surekha, B., Hanumanth Rao, D,. Krishnamohan Rao, G. \& P.R Vundavilli, (2013). Application of Response Surface Methodology for modeling the properties of Chromite-based resin bonded sand cores. International Journal of Mechanics. 7(4), 443- 458.

[4] Zych, J. (2013). Bench Life of Moulding and core sands with chemical binders- A new Ultrasonic Investigation Method. Archives of Foundry Engineering. 13(4), 117-122.

[5] Qing, J., Lekakh, S. \& Richards, V. (2013). No-bake Scontaining Mold- DI metal interactions: Consequences and Potential application. American Foundry Society. 13(1320).

[6] Ghosh, D. (2013). Modern furan for modern castings, Indian Foundry Congress. 
[7] LaFay, V. (2012). Application of No-Bake sodium silicate binder systems. American Foundry Society. International Journal of Metalcasting. 2012(Summer), 19-26.

[8] Saikaew, C. Weingwiset, S. (2012). Optimization of molding sand composition for quality improvement of iron castings. Applied Clay Science, Elsevier.

[9] Gresovnik, I., Kodelja, T., Vertnik, R., Sarler, B. (2012). Application of artificial neural networks to improve steel production process. Proceedings of the International Conference Artificial Intelligence and Soft Computing (pp.249-255).
[10] Hosadyna, M., Dobosz, St.M. \& Major-Gabrys, K. (2011). Influence of the hardener type on the sulphur diffusion from the moulding sand to the casting surface. Archives of Foundry Engineering. 11(2), 47-50.

[11] Htofuji, H. Tamura, M. \& Ito, H. (2010). Production of the 7-Ton Nonmagnetic Ductile iron Casting for largest class Power generator. Material transactions. 51, 103-109.

[12] Basheera, I.A. \& Hajmeer, M. (2000). Artificial neural networks: fundamentals computing, design, and application. Journal of Microbiological Methods. 43, 3-31. 